\title{
Viabilidade da antecipação do tratamento de sementes de arroz com inseticidas em relação à data de semeadura no controle de Oryzophagus oryzae (Coleoptera: Curculionidae)
}

\author{
Viability of the advance rice seed treatment with insecticides in relation to sowing date in the control \\ of Oryzophagus oryzae (Coleoptera: Curculionidae)
}

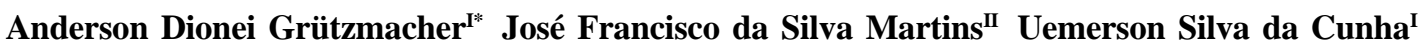 \\ Fabrizio Pinheiro Giolo ${ }^{I}$ Márcio Bartz das Neves ${ }^{\mathrm{I}}$ Wagner da Roza Härter ${ }^{\mathrm{I}}$ \\ Daniel Fernandez Franco ${ }^{\text {II }}$ Maria Laura Turino Mattos ${ }^{\text {II }}$
}

\section{RESUMO}

Oryzophagus oryzae (Costa Lima, 1936) é uma das pragas mais prejudiciais da cultura do arroz irrigado, sendo seu controle efetuado tradicionalmente com inseticidas granulados aplicados na água de irrigação. No entanto, o uso de inseticidas aplicados às sementes tem sido considerado promissor. Embora existam máquinas adequadas para aplicação de inseticidas às sementes, há dificuldade de assegurar a qualidade das sementes tratadas, em poucos dias ou mesmo horas antes da semeadura. Assim, objetivou-se avaliar a viabilidade do tratamento de sementes de arroz com inseticidas aplicados com antecedência à data de semeadura para o controle de O. oryzae. Dois experimentos foram instalados na Estação Experimental de Terras Baixas da Embrapa Clima Temperado, localizada no município de Capão do Leão, Rio Grande do Sul (RS), em duas épocas (1997/1998 e 2004/2005). O delineamento experimental foi em blocos ao acaso com quatro repetições. Foram avaliados os inseticidas carbosulfano e fipronil aplicados manualmente às sementes de arroz em diferentes épocas que antecederam a semeadura e foram avaliadas as variáveis poder germinativo e vigor das sementes, plantas emergidas, população larval e produtividade de grãos. O tratamento das sementes de arroz com inseticidas, antecipadamente à data de semeadura, visando ao controle de O. oryzae, demonstrou ser viável. Os inseticidas carbosulfano e fipronil são adequados ao tratamento antecipado das sementes, se aplicados até 75 dias antes da semeadura.

Palavras-chave: Oryza sativa, gorgulho-aquático, bicheirada-raiz, controle químico.

\section{ABSTRACT}

Oryzophagus oryzae (Costa Lima, 1936) is one of the most important pests of irrigated rice, whose control is made traditionally with granulated insecticides on the irrigation water. However, the use of insecticides on the seeds has been considered a promising method. Although there are adequate implements to apply insecticides on the seeds, it's hard to make this treatment with quality and in a big quantity, few days or hours before sowing. In this context, the viability of treat the rice seeds in an advance of sowing date has been evaluated. Two experiments were performed at Embrapa Clima Temperado, Capão do Leão, RS, Brazil in 1997/98 and 2004/05. The experimental design was in blocks at random with four repetitions, being evaluated the insecticides carbosulfan and fipronil applied manually to the seeds of rice in different times that preceded the sowing. Germination power and vigour, emerged plants, larval population and grains productivity were considered. The rice seeds treatment with insecticides in advance of sowing date trying to achieve the control of O. oryzae, demonstrate viability. The insecticides carbosulfan and fipronil are adequate to advance seeds treatment, if applied until 75 days before sowing.

Key words: Oryza sativa, rice water weevil, chemical control.

\section{INTRODUÇÃO}

A cultura do arroz irrigado por inundação no Brasil é atacada por diversas espécies de insetos, sendo Oryzophagus oryzae (Costa Lima, 1936) (Coleoptera: Curculionidae) uma das mais prejudiciais. O inseto adulto, denominado vulgarmente de gorgulhoaquático, invade os arrozais por ocasião da inundação, alimentando-se de tecidos superficiais das folhas de arroz. Ele acasala e oviposita principalmente em partes submersas da bainha foliar, dando origem às larvas

'Departamento de Fitossanidade, Faculdade de Agronomia “Eliseu Maciel”, Universidade Federal de Pelotas (UFPel), CP 354, 96010-900, Pelotas, RS, Brasil. E-mail: adgrutzm@ufpel.tche.br. *Autor para correspondência.

"Embrapa Clima Temperado, Pelotas, RS, Brasil. 
conhecidas por bicheira-da-raiz, as quais migram às raízes, onde se alimentam, podendo reduzir em até $25 \%$ a produtividade da cultura (MARTINS et al., 1997a; MARTINS et al., 2001; MARTINS et al., 2004).

Entre os métodos de controle de $\boldsymbol{O}$. oryzae, destaca-se o uso de inseticidas químicos (BOTTON et al., 1999; MARTINS et al., 2004; MARTINS et al., 2006), aplicados via tratamento de sementes (MARTINS et al., 1996a; MARTINS et al., 2000; GRÜTZMACHER et al., 2003), pulverização foliar cerca de três dias pósinundação dos arrozais (MARTINS et al., 1996b; MARTINS et al., 1997b) ou aplicação direta de produtos granulados em cobertura na lâmina da água de irrigação, 15 dias pós-inundação (MARTINS et al., 1993; MARTINS et al., 1996a).

Apesar de os três métodos de controle químico desse curculionídeo serem similarmente eficientes (BOTTON et al., 1999), há uma demanda por alternativas de aplicação de inseticidas que promovam a redução de custos de produção e maior segurança ambiental. Nesse contexto, possivelmente o tratamento de sementes apresenta-se como promissor (BOTTON et al., 1995; MARTINS et al., 1996a; CARBONARI et al., 1998; BOTTON et al.,1999; GRÜTZMACHER et al., 2003), principalmente se direcionado a áreas com histórico de ocorrência de $\boldsymbol{O}$. oryzae, podendo adicionalmente controlar outras espécies de insetospraga que vivem no solo e atacam a cultura no período pré-inundação (MARTINS et al., 2004; MARTINS et al., 2006). O tratamento de sementes, ao possibilitar redução da densidade de semeadura e, por conseguinte, diminuir dos gastos com sementes e inseticidas (CARBONARI et al., 1997; MARTINS al., 2004), poderá refletir em maior rentabilidade da cultura. Além disso, esse tratamento aparenta ser mais compatível com a preservação de determinados componentes do complexo faunístico dos arrozais irrigados, principalmente de insetos e aranhas (LINK et al., 2005; RODRIGUES et al., 2005), que habitam a parte aérea das plantas de arroz e potencialmente podem exercer o papel de agentes de controle biológico natural.

O tratamento de sementes de arroz, porém, apresenta alguns inconvenientes, entre os quais a prática de aplicar inseticidas em grande quantidade de sementes, em curto espaço de tempo, geralmente no mesmo dia da semeadura, principalmente para suprir os plantios extensivos feitos no Estado do Rio Grande do Sul. Apesar da disponibilidade de máquinas apropriadas para a aplicação de inseticidas nas sementes, há dificuldade para aliar a qualidade do tratamento, a segurança do operador e a quantidade de sementes tratadas em poucos dias ou mesmo horas antes da semeadura.
Os inseticidas fipronil e carbosulfano têm sido identificados como eficientes para controle de $\boldsymbol{O}$. oryzae por meio do tratamento de sementes realizado cerca de três horas antes da semeadura (BOTTON et al., 1999; GRÜTZMACHER et al., 2005). Nesse sentido, o objetivo deste trabalho foi avaliar a viabilidade de efetuar o tratamento de sementes de arroz com os inseticidas carbosulfano e fipronil, com a maior antecedência em relação à data de semeadura, sendo considerados aspectos relacionados com a eficiência no controle desse inseto e a manutenção da qualidade das sementes.

\section{MATERIAL E MÉTODOS}

Dois experimentos foram realizados na Estação Experimental Terras Baixas da Embrapa Clima Temperado, no município de Capão do Leão, Rio Grande do Sul (RS). O primeiro foi instalado na safra 1997/98, em delineamento de blocos casualizados, com quatro repetições e sete tratamentos, a saber: sementes de arroz (Oryza sativa) da cultivar "BRS Chuí”, tratadas com fipronil 250 SC (Standak $^{\circledR}$, grupo químico dos pirazóis), na dosagem de $62,5 \mathrm{~g}$ de i.a.100kg de sementes ${ }^{-1}$, aos 15, 30, 45, 60 e 75 dias antes da data de semeadura (DAS) e no dia da semeadura (0 DDS) mais a testemunha (sementes não-tratadas). O tratamento das sementes ( $2 \mathrm{~kg}$ ) com inseticida foi realizado em pacotes plásticos com capacidade para cinco litros, de modo a obter uma mistura homogênea da calda inseticida (1,5 litros $100 \mathrm{~kg}^{-1}$ ) com as sementes. Por ocasião da semeadura, foram retiradas amostras de $200 \mathrm{~g}$ de sementes, correspondentes a cada tratamento, para análise de vigor e germinação. As unidades experimentais (parcelas de $8 \mathrm{~m}^{2}$ ) consistiram de dez fileiras de plantas espaçadas de $0,2 \mathrm{~m}$ e $4 \mathrm{~m}$ de comprimento, com densidade de semeadura de 120 sementes $\mathrm{m}^{-1}$. Aos 25 dias após emergência (DAE), foi realizada a irrigação por inundação das parcelas, mantendo-se uma lâmina de água de $15 \mathrm{~cm}$ de espessura, evitando-se desuniformidade na infestação do inseto. Para impedir a mistura de tratamentos, as parcelas foram isoladas com taipas, estabelecendo-se entrada e saída individual da água de irrigação. A avaliação da população de larvas de $\boldsymbol{O}$. oryzae foi realizada aos 35 dias após a irrigação (DAI), foram retiradas quatro amostras de solo e raízes, com $\pm 8,5 \mathrm{~cm}$ de altura e $10 \mathrm{~cm}$ de diâmetro, duas foram retiradas na primeira fileira de plantas e duas na décima fileira, adotando-se técnica adaptada de TUGWELL \& STEPHEN (1981). A colheita de grãos foi feita nas oito fileiras de plantas centrais das parcelas.

O segundo experimento foi instalado na safra 2004/05, sendo adotados os procedimentos do 
experimento anterior, mas com as seguintes alterações: emprego da cultivar "BRS Taim”, aplicação de dois inseticidas no tratamento das sementes: carbosulfano 250 FS (Fenix ${ }^{\circledR}$, grupo químico dos metilcarbamatos de benzofuranila), na dosagem de $375 \mathrm{~g}$ de i.a. $100 \mathrm{~kg}^{-1} \mathrm{e}$ fipronil 250 SC $\left(\right.$ Standak $^{\circledR}$ ) na dosagem de $40 \mathrm{~g}$ de i.a.100 $\mathrm{kg}^{-1}$, ambos aplicados aos 12, 37, 57 e 76 DAS e no dia da semeadura (0 DDS) mais a testemunha (sementes não-tratadas). O inseticida carbofurano $100 \mathrm{GR}$ (Furadan 100 G, grupo químico dos metilcarbamatos de benzofuranila) foi usado como tratamento padrão na dosagem de $400 \mathrm{~g}$ de i.a.ha ${ }^{-1}$ em cobertura 25 DAI na água de irrigação das parcelas experimentais. Aos 10 DAE se realizou avaliação do número de plantas emergidas em toda a extensão da quarta fileira de cada parcela experimental. A avaliação da população de larvas do inseto foi realizada aos 25 e 40 DAI, de acordo com a metodologia adotada no primeiro experimento.

Em ambos os experimentos, os dados foram submetidos à análise de variância e as médias foram comparadas pelo teste de Tukey com 5\% de significância. Com base no teste de Hartley, não foi realizada transformação dos dados para a análise estatística. A mortalidade média de larvas foi corrigida pela fórmula de Abbott (ABBOTT, 1925), a qual foi usada para o cálculo da eficiência dos inseticidas.

\section{RESULTADOS E DISCUSSÃO}

Os resultados do primeiro experimento evidenciaram que o tratamento de sementes de arroz da cultivar "BRS Chuí” com fipronil 250 SC, na dosagem de $62,5 \mathrm{~g}$ de i.a. $100 \mathrm{~kg}^{-1}$, em diferentes épocas antes da semeadura, bem como na semeadura, não afetou a germinação e o vigor das sementes. Esses resultados evidenciaram que a aplicação do fipronil nas sementes de arroz, em até 75 dias antes da semeadura (DAS), não interferiram na qualidade fisiológica das sementes. Esses resultados confirmam os obtidos por BOTTON et al. (1999), os quais avaliaram os inseticidas carbosulfano, na dosagem de $300 \mathrm{~g}$ de i.a. $100 \mathrm{~kg}^{-1}$, e fipronil, nas dosagens de 50 e 75 de i.a. $100 \mathrm{~kg}^{-1}$. Os tratamentos antecipados das sementes foram eficientes no controle da população de larvas de $\boldsymbol{O}$. oryzae, com índices de 94\% a 98\%, sendo significativamente iguais ao do tratamento realizado na data da semeadura (Tabela 1). Contudo, o controle exercido pelo fipronil não refletiu em aumentos de produtividade significativamente superiores ao da testemunha (Tabela 1). Possivelmente o nível de infestação do inseto detectado na testemunha (12 larvas por amostra) não tenha causado dano suficiente às raízes a ponto de causar uma redução significativa da produção de grãos, mesmo sendo superior a cinco larvas por amostra, o qual é o nível populacional indicado para controle econômico do inseto (SOCIEDADE, 2005). Ademais, diferenças significativas entre tratamentos quanto à produção de grãos de arroz, constatada em trabalhos de pesquisa com $\boldsymbol{O}$. oryzae, têm sido atribuídas à resistência (tolerância) de cultivares ao inseto (MARTINS \& TERRES, 1995; SILVA et al., 2003).

Tabela 1 - Qualidade das sementes, população larval de Oryzophagus oryzae e produtividade de arroz "BRS Chuí” tratadas antes da semeadura com fipronil 250 SC ${ }^{1}$. Capão do Leão, RS, 1997/1998.

\begin{tabular}{|c|c|c|c|c|c|}
\hline \multirow{2}{*}{ Tratamentos $^{2}$} & \multicolumn{2}{|c|}{----------Sementes---------- } & \multicolumn{2}{|c|}{----------População larval--------- } & \multirow{2}{*}{ Produtividade de grãos $\left(\mathrm{kg} \mathrm{ha}^{-1}\right)$} \\
\hline & $\mathrm{G}(\%)^{3}$ & Vigor (\%) & Larvas $\left(n^{\circ}\right)^{4}$ & Controle $(\%)^{5}$ & \\
\hline 0 DDS & $95,0 a^{6}$ & 96,0 a & $0,4 \mathrm{~b}$ & 97,0 & $4692,0 \mathrm{a}$ \\
\hline 15 DAS & $96,0 \mathrm{a}$ & 93,0 a & $0,6 \mathrm{~b}$ & 95,0 & 5196,0 a \\
\hline 30 DAS & 94,0 a & 94,0 a & $0,8 \mathrm{~b}$ & 94,0 & 4606,0 a \\
\hline 45 DAS & 94,0 a & $91,0 \mathrm{a}$ & $0,2 \mathrm{~b}$ & 98,0 & 4389,0 a \\
\hline 60 DAS & 95,0 a & $95,0 \mathrm{a}$ & $0,4 \mathrm{~b}$ & 97,0 & $4305,0 \mathrm{a}$ \\
\hline 75 DAS & 96,0 a & $92,0 \mathrm{a}$ & $0,6 \mathrm{~b}$ & 95,0 & 4574,0 a \\
\hline Testemunha & $94,0 \mathrm{a}$ & $90,0 \mathrm{a}$ & $12,4 \mathrm{a}$ & - & $4628,0 \mathrm{a}$ \\
\hline Média & 94,9 & 93 & 2,2 & 96 & 4627,1 \\
\hline $\mathrm{CV}(\%)$ & 0,9 & 2,3 & 27,8 & - & 6,2 \\
\hline
\end{tabular}

${ }^{1}$ Standak 250 SC: 62,5 g de i.a.100kg de sementes ${ }^{-1}$.

${ }^{2}$ Tratamento das sementes no dia da semeadura (0 DDS), 15, 30, 45, 60 e 75 dias antes da semeadura (DAS).

${ }^{3}$ Germinação (G).

${ }^{4}$ Número médio de larvas por amostra padrão de solo e raízes (nํㅜ) aos 35 dias após a irrigação.

${ }^{5}$ Eficiência de controle corrigida pela fórmula de Abbott (ABBOTT, 1925).

${ }^{6}$ Médias não seguidas por letras idênticas, na coluna, diferem pelo teste de Tukey em nível de 5\% de probabilidade de erro.

Ciência Rural, v.38, n.7, out, 2008. 
No segundo experimento, não foram constatadas diferenças significativas quanto ao número de plantas emergidas entre a testemunha e os tratamentos antecipados das sementes de arroz da cultivar "BRS Taim” com fipronil e carbosulfano, bem como quanto à época da semeadura (Tabela 2). Considerando que esse resultado foi obtido quando a infestação de larvas foi baixa, ficou evidente que o número de plantas emergidas decorreu do fato de que os inseticidas aplicados antes da semeadura ou mesmo nessa ocasião não afetaram a qualidade das sementes da cultivar “BRS Taim”. Assim, esses resultados confirmam aqueles obtidos no primeiro experimento, quando foi constatado que a antecipação do tratamento das sementes com fipronil, até 75 DAS, não causou alterações na germinação e no vigor das sementes (Tabela 1).

Em relação à eficiência de controle de $\boldsymbol{O}$. oryzae, foi constatado que, tanto aos 25 DAI como aos $40 \mathrm{DAI}$, todos os tratamentos antecipados com fipronil proporcionaram redução da população larval de 99\% a 100\%, comparativamente à aplicação na data da semeadura (Tabela 2). Na avaliação aos 40 DAI, todos os tratamentos com fipronil apresentaram eficiência de controle igual a do inseticida padrão carbofurano, quando foi aplicado em cobertura na superfície da lâmina da água de irrigação do arroz.

Os tratamentos antecipados das sementes com carbosulfano reduziram a população de larvas de O. oryzae de, no mínimo, $71 \%$ a $74 \%$ aos 25 e 40 aos DAI, respectivamente, não havendo diferença significativa entre os tratamentos com esse inseticida aplicados nas diferentes épocas que antecederam a semeadura ou mesmo nessa ocasião. Todavia, esses tratamentos foram menos eficientes que os tratamentos com fipronil (Tabela 2). Assim, apesar da menor eficiência de carbosulfano no controle do inseto e conforme constatado por GRÜTZMACHER et al. (2005), em avaliação da aplicação antecipada dos inseticidas carbosulfano e fipronil, evidenciou-se que independentemente da época do tratamento das sementes com inseticidas em relação à data de semeadura não ocorreu redução na eficiência de controle. Tais resultados também corroboram os obtidos por MARTINS et al. (2000), os quais observaram que a aplicação antecipada de fipronil, na

Tabela 2 - Efeito dos inseticidas fipronil 250 SC e carbosulfano 250 FS, aplicados no tratamento das sementes de arroz cultivar "BRS Taim”, antes da semeadura, sobre a emergência de plantas, população larval de Oryzophagus oryzae e produtividade de grãos. Capão do Leão, RS, 2004/2005.

\begin{tabular}{|c|c|c|c|c|c|c|}
\hline \multirow[t]{2}{*}{ Tratamentos $^{1}$} & \multirow[t]{2}{*}{$\begin{array}{c}\text { Plantas } \\
\text { emergidas }\left(\mathrm{n}^{\mathrm{o}}\right)^{2}\end{array}$} & \multicolumn{2}{|c|}{25 DAI } & \multicolumn{2}{|c|}{40 DAI } & \multirow[t]{2}{*}{$\begin{array}{l}\text { Produtividade de grãos } \\
\qquad\left(\mathrm{kg} \mathrm{ha}^{-1}\right)\end{array}$} \\
\hline & & Larvas $\left(n^{-0}\right)^{3}$ & Controle $(\%)^{4}$ & Larvas $\left(\mathrm{n}^{\circ}\right)$ & Controle (\%) & \\
\hline Fipronil 0 DDS & $123,0 \mathrm{a}^{5}$ & $0,12 \mathrm{ab}$ & 99,0 & $0,00 \mathrm{a}$ & 100,0 & 5219,0 a \\
\hline Fipronil 12 DAS & $165,0 \mathrm{a}$ & $0,00 \mathrm{a}$ & 100,0 & $0,00 \mathrm{a}$ & 100,0 & $5124,0 \mathrm{a}$ \\
\hline Fipronil 37 DAS & $139,0 \mathrm{a}$ & $0,06 \mathrm{a}$ & 99,0 & $0,00 \mathrm{a}$ & 100,0 & 5286,0 a \\
\hline Fipronil 57 DAS & $142,0 \mathrm{a}$ & $0,12 a b$ & 99,0 & $0,00 \mathrm{a}$ & 100,0 & 5083,0 a \\
\hline Fipronil 76 DAS & $130,0 \mathrm{a}$ & $0,00 \mathrm{a}$ & 100,0 & $0,00 \mathrm{a}$ & 100,0 & 5259,0 a \\
\hline Carbosu 00 DDS & $138,0 \mathrm{a}$ & 1,56 bc & 83,0 & $1,92 \mathrm{~b}$ & 78,0 & 5006,0 a \\
\hline Carbosu 12 DAS & $144,0 \mathrm{a}$ & $1,63 \mathrm{c}$ & 82,0 & $2,27 \mathrm{~b}$ & 74,0 & 5146,0 a \\
\hline Carbosu 37 DAS & $160,0 \mathrm{a}$ & $2,62 \mathrm{c}$ & 71,0 & $1,25 a b$ & 86,0 & 5317,0 a \\
\hline Carbosu 57 DAS & $141,0 \mathrm{a}$ & $2,42 \mathrm{c}$ & 74,0 & $1,60 \mathrm{~b}$ & 82,0 & 5114,0 a \\
\hline Carbosu 76 DAS & $151,0 \mathrm{a}$ & $1,77 \mathrm{c}$ & 81,0 & $2,00 \mathrm{~b}$ & 77,0 & 5133,0 a \\
\hline Carbofu 25 DAI & - & - & - & 0,00 a & 100,0 & $5010,0 \mathrm{a}$ \\
\hline Testemunha & $164,0 \mathrm{a}$ & $9,18 \mathrm{~d}$ & - & $8,80 \mathrm{c}$ & - & 4929,0 a \\
\hline Média & 145,2 & 1,8 & 88,8 & 1,5 & 90,6 & 5135,5 \\
\hline CV (\%) & 13,1 & 33,9 & - & 39,5 & - & 2,3 \\
\hline
\end{tabular}

${ }^{1}$ Tratamento das sementes no dia da semeadura (0 DDS), 12, 37, 57 e 76 dias antes da semeadura (DAS): Fipronil (Standak 250 SC, $40 \mathrm{~g}$ de i.a.100kg de sementes ${ }^{-1}$ ); carbosulfano= Carbosu (Fênix $250 \mathrm{FS}$, 375g de i.a.100kg de sementes ${ }^{-1}$ ); carbofurano= Carbofu $($ Furadan $100 \mathrm{G}$, $400 \mathrm{~g}$ de i.a. $\mathrm{ha}^{-1}$ ), aplicado na água de irrigação aos 25 dias após a irrigação (DAI).

${ }^{2}$ Total de plantas em quatro metros de fileira.

${ }^{3}$ Número médio de larvas por amostra padrão de solo e raízes.

${ }^{4}$ Eficiência de controle corrigida pela fórmula de Abbott (ABBOTT, 1925).

${ }^{5}$ Médias não seguidas por letras idênticas, na coluna, diferem pelo teste de Tukey em nível de 5\% de probabilidade de erro. 
dosagem de $62,5 \mathrm{~g}$ de i.a.100 $\mathrm{kg}^{-1}$, proporcionou uma eficiência de controle de larvas de $\boldsymbol{O}$. oryzae semelhante à aplicação realizada no ato da semeadura.

Também não foram constatadas diferenças significativas quanto à produtividade de grãos entre os tratamentos químicos aplicados às sementes e à testemunha (Tabela 2). Esses resultados podem ser atribuídos à infestação larval de nove larvas por amostra, a qual pode não ter sido suficiente para reduzir significativamente a produção de grãos na cultivar "BRS Taim”.

Com base nos resultados obtidos nos dois experimentos, considera-se que o tratamento antecipado de sementes de arroz com inseticidas em relação à data de semeadura constitui-se em mais uma opção ao agricultor no manejo integrado de O. oryzae, permitindo inclusive flexibilidade quanto ao período de utilização de equipamentos destinados ao tratamento das sementes.

\section{CONCLUSÕES}

A aplicação de inseticidas em sementes de arroz, antecipadamente em relação à data de semeadura, é viável para o controle de $\boldsymbol{O}$. oryzae. Os inseticidas carbosulfano e fipronil são adequados para o tratamento das sementes de arroz, visando ao controle de $\boldsymbol{O}$. oryzae, se aplicados até 75 dias antes da semeadura.

\section{REFERÊNCIAS}

ABBOTT, W.S. A method of computing the effectiveness of an insecticide. Journal of Economic Entomology, Lanham, v.18, p.265-267, 1925.

BOTTON, M. et al. Comparação de métodos de controle químico de Oryzophagus oryzae na cultura do arroz irrigado. In: REUNIÃO DA CULTURA DO ARROZ IRRIGADO, 21., 1995, Porto Alegre, RS. Anais... Porto Alegre: IRGA, 1995. p.217-220.

BOTTON, M. et al. Eficiência de métodos de aplicação de inseticidas no controle de Oryzophagus oryzae (Costa Lima, 1936) (Coleoptera: Curculionidae), na cultura do arroz irrigado. Pesquisa Agropecuária Gaúcha, Porto Alegre, v.5, p.7175, 1999.

CARBONARI, J.J. et al. Efeito do tratamento químico de sementes de arroz na população larval de Oryzophagus oryzae. In: CONGRESSO BRASILEIRO DE ENTOMOLOGIA, 16. 1997, Salvador, BA. Resumos... Salvador: SEB, 1997. p.177.

CARBONARI, J.J. et al. Influência do tratamento químico de sementes associado a densidades de semeadura sobre Oryzophagus oryzae na cultura do arroz irrigado. In: CONGRESSO BRASILEIRO DE ENTOMOLOGIA, 17., 1998, Rio de Janeiro, RJ. Resumos... Rio de Janeiro: SEB, 1998. p.347.
GRÜTZMACHER, A.D. et al. Chemical control of Oryzophagus oryzae (Costa Lima, 1936) (Coleoptera: Curculionidae) on flooded rice by seed treatment. Revista Brasileira de Agrociência, Pelotas, v.9, p.379-382, 2003.

GRÜTZMACHER, A.D. et al. Efeito do tratamento antecipado de sementes de arroz irrigado com os inseticidas fipronil e carbosulfano no controle de Oryzophagus oryzae (Costa Lima, 1936) (Coleoptera: Curculionidae). In: CONGRESSO BRASILEIRO DE ARROZ IRRIGADO, 4.; REUNIÃO DA CULTURA DO ARROZ IRRIGADO, 26., 2005, Santa Maria, RS. Anais... Santa Maria: Orium, 2005. p.60-62.

LINK, D. et al. Aranhas associadas à cultura do arroz irrigado. In: CONGRESSO BRASILEIRO DE ARROZ IRRIGADO, 4.; REUNIÃO DA CULTURA DO ARROZ IRRIGADO, 26., 2005, Santa Maria, RS. Anais... Santa Maria: Orium, 2005. p.29-30.

MARTINS, J.F. da S.; TERRES, A.L.S. Avaliação de germoplasma de arroz visando resistência a Oryzophagus oryzae (Costa Lima). Anais da Sociedade Entomológica do Brasil, Londrina, v.24, p.445-453, 1995.

MARTINS, J.F. da S. et al. Alternativas de controle da bicheirada-raiz visando menor impacto ambiental. Lavoura Arrozeira, Porto Alegre, v.46, p.12-14, 1993.

MARTINS, J.F. da S. et al. Efeito do tratamento de sementes de arroz com inseticidas no controle de Oryzophagus oryzae (Costa Lima) (Coleoptera: Curculionidae) na cultura do arroz irrigado. Revista Brasileira de Agrociência, Pelotas, v.2, p.27-32, 1996a.

MARTINS, J.F. da S. et al. Controle de Oryzophagus oryzae (Costa Lima) através da pulverização foliar de arroz com inseticidas piretróides. Anais da Sociedade Entomológica do Brasil, Londrina, v.25, p.217-221, 1996b.

MARTINS, J.F. da S. et al. Manejo integrado do gorgulho aquático [Oryzophagus oryzae (Costa Lima, 1936)] na cultura do arroz irrigado: Situação atual e perspectivas futuras. In: REUNIÃO SUL BRASILEIRA SOBRE PRAGAS-DE-SOLO, 7., 1997, Santa Maria, RS. Anais e Ata... Santa Maria: UFSM, CCR, Departamento de Defesa Fitossanitária, 1997a. p.68-78.

MARTINS, J.F. da S. et al. Efeito da época de pulverização foliar de arroz com inseticidas piretróides no controle da bicheira-da-raiz [Oryzophagus oryzae (Lima,1936)]. Lavoura Arrozeira, Porto Alegre, v.50, p.11-14, 1997b.

MARTINS, J.F. da S. et al. Tratamento de sementes de arroz para o controle do gorgulho aquático e redução da densidade de semeadura. Embrapa Clima Temperado, 2000. 2p. (Embrapa Clima Temperado. Recomendação Técnica, 01).

MARTINS, J.F. da S. et al. Gorgulho-aquático-do-arroz, Oryzophagus oryzae (Coleoptera: Curculionidae). In: VILELA, E.F. et al. (Ed.). Histórico e impacto das pragas introduzidas no Brasil, com ênfase na fruticultura. Ribeirão Preto: Holos, 2001. p.128-134.

MARTINS, J.F. da S. et al. Descrição e manejo integrado de insetos-praga em arroz irrigado. In: GOMES, A.S.; MAGALHÃES Jr., A.M. Arroz irrigado no sul do Brasil. Brasília: Embrapa Informação Tecnológica, 2004. p.635-675. 
MARTINS, J.F. da S. et al. Pragas do arroz irrigado. In MAGALHÃES Jr. et al. Sistema de cultivo de arroz irrigado no Brasil. Pelotas: Embrapa Clima Temperado, 2006. p.197212. (Embrapa Clima Temperado. Sistema de Produção, 03).

RODRIGUES, E.N.L. et al. Aranhas e suas formas de predação na cultura do arroz irrigado (Oryza sativa) na Depressão Central, RS. In: CONGRESSO BRASILEIRO DE ARROZ IRRIGADO, 4.; REUNIÃO DA CULTURA DO ARROZ IRRIGADO, 26. 2005, Santa Maria, RS. Anais... Santa Maria: Orium, 2005. p.31-33.
SILVA, F.F. et al. Avaliação da resistência de arroz a Oryzophagus oryzae com e sem chance de escolha da planta hospedeira. Revista Brasileira de Agrociência, Pelotas, v.9, p.135-140, 2003.

SOCIEDADE SUL-BRASILEIRA DE ARROZ IRRIGADO (SOSBAI). Arroz irrigado: recomendações técnicas para o sul do Brasil. Santa Maria: SOSBAI, 2005. 159p.

TUGWELL, W.P.; STEPHEN, F.M. Rice water weevil seasonal abundance, economic levels and sequential sampling plant. Fayeltville: Agricultural Experiment Station, 1981. 16p. (Bulletin n. 849). 